\title{
The relationship between polymorphisms of XRCC5 genes with astrocytoma prognosis in the Han Chinese population
}

\author{
Xue He ${ }^{1,2,3, *}$, Xikai Zhu ${ }^{1,2,3, *}$, Lei $\mathrm{Li}^{4,5}$, Jiayi Zhang ${ }^{6}$, Ruipeng Wu ${ }^{1,2,3}$, Yuan Zhang ${ }^{1,2,3}$, \\ Longli Kang ${ }^{1,2,3}$, Dongya Yuan ${ }^{1,2,3}$, Tianbo Jin ${ }^{1,2,3,6}$ \\ ${ }^{1}$ Key Laboratory for Molecular Genetic Mechanisms and Intervention Research on High Altitude Disease of Tibet Autonomous \\ Region, School of Medicine, Xizang Minzu University, Xianyang, Shaanxi 712082, China \\ ${ }^{2}$ Key Laboratory for Basic Life Science Research of Tibet Autonomous Region, School of Medicine, Xizang Minzu University, \\ Xianyang, Shaanxi 712082, China \\ ${ }^{3}$ Key Laboratory of High Altitude Environment and Gene Related to Disease of Tibet Ministry of Education, School of Medicine, \\ Xizang Minzu University, Xianyang 712082, Shaanxi, China \\ ${ }^{4}$ Department of Thoracolumbar Spine Surgery, Second Affiliated Hospital of Inner Mongolia Medical University, Hohhot \\ 010000, China \\ ${ }^{5}$ Inner Mongolia Medical University, Hohhot, Inner Mongolia 010050, China \\ ${ }^{6}$ Key Laboratory of Resource Biology and Biotechnology in Western China, Ministry of Education, School of Life Sciences, \\ Northwest University, Xi'an 710069, China \\ "joint first authors \\ Correspondence to: Tianbo Jin, email: jintianbo@gmail.com \\ Dongya Yuan, email: dyyuanxzmz@gmail.com
}

Keywords: astrocytoma, prognosis, overall survival, single nucleotide polymorphism

Received: May 30, 2016

Accepted: October 26, 2016

Published: November 11, 2016

\section{ABSTRACT}

Background: Gliomas are highly malignant with a poor prognosis. Studies have reported that DNA repair genes influence risk for glioma, but its relationship with prognosis is unclear. In this study, we want to explore the relationship between DNA repair genes (XRCC3, XRCC4 and XRCC5) and prognosis of astrocytoma in the Chinese Han population.

Materials and Methods: 160 astrocytoma cases were recruited in our study. Survival probabilities were estimated by using Kaplan-Meier analysis, and significant differences were analyzed by using the log-rank test. Cox proportional hazards models were used to analyze the associations between genotypes with astrocytoma survival. Hazard ratios (HR) and $95 \%$ confidence intervals (CI) were estimated using multivariable models. All tests were two-sided and $p<0.05$ was considered to be significant.

Results: The SNP (rs9288516) in XRCC5 (HR: 1.69, 95\%CI: $1.04-2.77, p=0.049$ ), surgical approach (HR: 0.61, 95\%CI: $0.43-0.88, p=0.003$ ) and chemotherapy (HR: $0.71,95 \% \mathrm{CI}: 0.50-0.99, p=0.029$ ) were associated with astrocytoma prognosis. Further, the "A/A" genotype of rs9288516 in XRCC5 (HR: 1.67, 95\%CI: $1.02-2.72, p$ $=0.042$ ) had significantly outcomes after adjusting for potential confounders, patients with poor tumor differentiation and the coexistence of the unfavorable genotypes.

Conclusion: These results suggest that polymorphisms of XRCC5 play an important role in astrocytoma prognosis in the Chinese Han population which could be used in the determination of astrocytoma prognosis in clinical researches.

\section{INTRODUCTION}

Astrocytoma is a tumor composed of astrocytes, which is the most common type of neural epithelial tumor [1]. Astrocytoma is an invasive growth tumor, the majority of tumor possible recurrence after surgical resection, and the recurrence of the tumor can evolve into anaplastic astrocytoma or pleomorphic glioblastoma. In recent years, the world's major cancer research center has been committed to the study 
of astrocytoma prognosis of the scholars dedicate themselves to looking for more effective treatment method all around the world. At present, we have no uniform standard about the prognosis and treatment of glioma in domestic and foreign.

The previous literature has recorded the main method to evaluate the prognosis and treatment: 1, $\mathrm{CT}$ and other imaging results as a determination of indicators, mainly through a period of time after treatment to determine the change in tumor volume; 2 , Survival rate and survival time were used as indicators: survival rate of 1 year, 3 year and 5 year survival rate of tumor patients were observed and survival curves were drawn. The curative effect and prognosis of different treatment groups were observed; 3 , the change of the functional status of the patients before and after the treatment was judged [2]. The factors which affect the prognosis of astrocytoma are complicated including age, gender, tumor size, pathological grading, surgical resection, postoperative radiotherapy, KPS (Karnofsky performance Status), chemotherapy and other factors [3-5].

Liu Y, et al. analyzed the effect of NHEJ pathway gene (eg: XRCC5, XRCC4 gene) on glioma in 771 case and 752 controls, found that rs3770502 and rs9288516 in XRCC5 gene and rs1056503 in XRCC4 gene increased the risk of glioma $[6,7]$. Zhou et al. analyzed the effect of XRCC3 gene on glioma risk, found that rs861530 and rs3212092 in XRCC3 gene increased the risk of glioma [8]. But, the relationship between these loci and the prognosis of astrocytoma is not clear. So, we want to determine the effect of DNA repair genes (XRCC3, $X R C C 4$ and $X R C C 5$ ) on the prognosis of astrocytoma in our research.

\section{RESULTS}

\section{Characteristics of the patients}

Specimens from 160 astrocytomas patients (male, 88; female, 72) were available for analysis. 66 cases was less than forty years old and 94 cases were over forty years old in the astrocytomas patients. The pathologic stage distribution was: stage I 18 cases, stage II 78 cases, stage III 64 cases. The 1 and 3 year of the OS of astrocytoma patients were $28.8 \%$ and $6.6 \%$, respectively. The characteristic of astrocytomas patients was shown in Tables 1 and 2 .

\section{Univariate analysis}

As shown in Table 2, we found that better prognosis in astrocytoma patients with total resection (astrocytoma: OS: $p=0.003$ ). The 1-year survival of astrocytoma patient with total resection was higher than those with not all resection, respectively. The 1-year survival of astrocytoma patient with total resection was $34.2 \%$, while the 1 -year survival of the not all resection astrocytoma patient was $16.3 \%$.

Better prognosis in astrocytoma patients with accept Chemotherapy (OS: $p=0.029$ ). The 1-year survival of astrocytoma patient who accept chemotherapy were $37.9 \%$, which were higher than the patient without chemotherapy treatment (1-year survival: $39.4 \%$ vs. 23.5\%) (Table 2).

No significant association was found between the prognosis of astrocytomas and selected demographic characteristics such as sex, age, WHO classification, and radiotherapy.

We further explored the role of genetic polymorphisms in the prognosis of astrocytoma, significant association was observed in our study (Table 3). Kaplan-Meier survival curves graphically also emphasize that the "A/A" genotype of rs9288516 in XRCC5 (X-ray cross-complementing 5) has effect on OS in astrocytomas patients (1-year survival of TT vs. AA: $25 \%$ vs. $17.9 \%$ ), which also shorten the astrocytoma patient's survival time, and astrocytoma patients with poor prognosis $(\mathrm{HR}=1.69)$ (Figure 1).

\section{Multivariate analysis}

Univariate analysis found that extent of surgical resection and chemotherapy affect the prognosis of astrocytoma patients. Therefore, Multivariate analysis, adjusted for extent of surgical resection and chemotherapy, found that unfavorable genotypes (the "A/A" genotype of rs9288516 in XRCC5) had significant outcomes (HR: 1.67, 95\% CI: $1.02-2.72, p=0.042$ ), which were displayed in Table 4.

\section{DISCUSSION}

The findings of this study suggested an association surgical approach, chemotherapy, SNP in the XRCC5 gene and the risk for astrocytoma prognosis in Xi'an population. The results indicated that surgical approach, chemotherapy and XRCC5 gene influence the prognosis of astrocytoma patients.

\section{Surgical approach}

At present, the majority of scholars had realized that it is the first choice to cure astrocytoma by surgical treatment, which would alleviate the oppression of the surrounding tissue and improve the therapeutic effect. It has been reported that there were significant differences between the total resection and partial resection of the tumor and the length of survival time of malignant glioma is related to tumor resection [9]. The study had confirmed that the 1 and 3 year survival rate of total resection of the tumor $(35.92 \%, 8.9 \%)$ was significantly higher than 
Table 1: clinical characteristics of astrocytoma patients

\begin{tabular}{|c|c|c|c|}
\hline \multirow{2}{*}{ Variety } & \multirow{2}{*}{ Classification } & \multicolumn{2}{|c|}{ Astrocytoma } \\
\hline & & Case(s) & Proportion (\%) \\
\hline \multirow{2}{*}{ Sex } & Male & 88 & 55 \\
\hline & Female & 72 & 45 \\
\hline \multirow{2}{*}{ Age } & $<40$ years & 66 & 41.3 \\
\hline & $\geq 40$ years & 94 & 58.8 \\
\hline \multirow{3}{*}{ WHO classification } & WHO I grade & 18 & 11.3 \\
\hline & WHO II grade & 78 & 48.8 \\
\hline & WHO III grade & 64 & 40.0 \\
\hline \multirow{2}{*}{$\begin{array}{l}\text { The extent of surgical } \\
\text { resection }\end{array}$} & Total resection & 111 & 69.4 \\
\hline & Not all & 49 & 30.6 \\
\hline \multirow{3}{*}{ Radiotherapy } & Gamma knife & 106 & 66.3 \\
\hline & Conformal radiotherapy & 41 & 25.6 \\
\hline & Not done & 13 & 8.1 \\
\hline \multirow{4}{*}{ Chemotherapy } & Platinum containing regimens & 37 & 23.1 \\
\hline & Nimustinecontaining regimens & 14 & 8.8 \\
\hline & Temozolomide containing regimens & 7 & 4.4 \\
\hline & Not done & 102 & 63.8 \\
\hline \multirow{3}{*}{ State of survival } & Survival & 6 & 3.8 \\
\hline & Loss to follow-up & 7 & 4.4 \\
\hline & Death & 147 & 91.9 \\
\hline \multirow{3}{*}{ State of progress } & No progress & 6 & 3.8 \\
\hline & Progress & 152 & 95.0 \\
\hline & Missing & 2 & 1.3 \\
\hline
\end{tabular}

Table 2: Univariate cox regression analysisof prognostic factors for overall survival rates of astrocytoma patients

\begin{tabular}{|c|c|c|c|c|c|c|}
\hline Variety & Classification & $\begin{array}{c}\text { Death cases/ } \\
\text { Total cases }\end{array}$ & $\begin{array}{c}\text { Median } \\
\text { survival time }\end{array}$ & $\begin{array}{c}1 \text { year/3 year } \\
\text { overall survival }\end{array}$ & $p$ & HR(95\%CI) \\
\hline Total & l & $147 / 160$ & 11 & $28.8 \% / 6.6 \%$ & l & / \\
\hline \multirow[t]{2}{*}{ Sex } & Male & $80 / 88$ & 11 & $26.1 \% / 6.8 \%$ & 0.769 & 1 \\
\hline & Female & $67 / 72$ & 11 & $31.9 \% / 6.3 \%$ & & $1.05(0.76-1.44)$ \\
\hline \multirow[t]{2}{*}{ Age } & $<$ 40years & $58 / 66$ & 11 & $31.8 \% / 8.6 \%$ & 0.186 & 1 \\
\hline & $\geq 40$ years & $89 / 94$ & 10 & $26.6 \% /-$ & & $1.23(0.88-1.71)$ \\
\hline $\begin{array}{l}\text { WHO } \\
\text { classification } \\
\text { extent of } \\
\text { surgical } \\
\text { resection }\end{array}$ & I-II grade & $86 / 96$ & 11 & $28.1 \% /$ & 0.612 & 1 \\
\hline
\end{tabular}

(Continued) 


\begin{tabular}{|c|c|c|c|c|c|c|}
\hline Variety & Classification & $\begin{array}{l}\text { Death cases/ } \\
\text { Total cases }\end{array}$ & $\begin{array}{c}\text { Median } \\
\text { survival time }\end{array}$ & $\begin{array}{l}1 \text { year } / 3 \text { year } \\
\text { overall survival }\end{array}$ & $p$ & HR(95\%CI) \\
\hline & III grade & $61 / 64$ & 11 & $29.7 \% / 3.9 \%$ & & $1.08(0.78-1.50)$ \\
\hline & Not all resection & $98 / 111$ & 9 & $16.3 \% /-$ & 0.003 & 1 \\
\hline & Total resection & $49 / 49$ & 11 & $34.2 \% / 9.6 \%$ & & $0.61(0.43-0.88)$ \\
\hline \multirow[t]{3}{*}{ Radiotherapy } & No & $11 / 14$ & 12 & $46.2 \% /-$ & 0.334 & 1 \\
\hline & $\begin{array}{c}\text { Conformal } \\
\text { radiotherapy }\end{array}$ & $38 / 41$ & 9 & $14.6 \% / 8.8 \%$ & & $1.48(0.75-2.91)$ \\
\hline & Gamma knife & $99 / 106$ & 11 & $32.1 \% /-$ & & $1.18(0.63-2.21)$ \\
\hline \multirow[t]{2}{*}{ Chemotherapy } & No & $96 / 102$ & 9 & $23.5 \% /-$ & 0.029 & 1 \\
\hline & Yes & $51 / 58$ & 12 & $37.9 \% / 11.4 \%$ & & $0.71(0.49-0.99)$ \\
\hline
\end{tabular}

$p<0.05$ indicates statistical significance; HR: hazard ratios; CI: confidence interval.

the partial resection of the tumor $(17.6 \%, 1.2 \%)$. In our research, we found that better prognosis in astrocytoma patients with total resection. The 1 year survival rates of astrocytoma patient with total resection were $34.2 \%$, while the 1 year survival rates of the not all resection astrocytoma patient was $16.3 \%$. The 1 year survival rates of astrocytoma patient with total resection were higher than those with not all resection, respectively The extent of tumor resection would affect the prognosis, which is one of the independent factors affected the prognosis. The degree of tumor resection is cleaner, the prognosis is better.

\section{Chemotherapy}

Even if surgery has achieved good results in the treatment of glioma, possiblity to recur for most tumors, chemotherapy is one of method to inhibit the progression of astrocytoma, while the treatment outcome was poor. The main reason is the existence of drug resistance and blood brain barrier factors and so on. Although the effect is unsatisfactory, there is still a certain function. In our study, we found that the univariate analysis showed that chemotherapy was statistically significant, 1 and 3year survival rate was significantly higher $(39.4 \%, 12.7 \%)$ than patients who did not receive chemotherapy $(24.1 \%, 2.7 \%)$. Stewart et al. has used the Meta analysis about the effect of chemotherapy for malignant glioma [10]. The results had showed that patient of glioma received chemotherapy, whose 1 years survival rate increased by $6 \% ; 2$ years survival rate of glioblastoma increased by $4 \%$, the average survival time was prolonged for 2 months. So, to a certain extent, astrocytoma patient accepted chemotherapy may have positive role.

\section{$X R C C 5$ gene and prognosis of astrocytoma}

By multivariate cox regression analysis, we found that rs9288516 in XRCC5 gene influence the prognosis of astrocytoma patient. Kaplan-Meier curves and logrank results revealed that astrocytoma patients carrying genotype AA rs9288516 had shorter survival time than those with genotype AT and TT alone. Consistently, astrocytoma patients carrying AA genotype at rs 9288516 also had worse survival. It was also reported that $X R C C 5$ gene polymorphism effect the prognostic of hepatocellular Carcinoma and melanoma, as a risk factor $[11,12]$.

XRCC5 (X-ray repair cross-complementing gene 5 ) is one of the double-strand break repair genes, which plays an important role in non-homologous terminal repair. The Ku80 protein was encoded by the XRCC5, and KU70 protein was encoded by the XRCC6 [13]. KU80 protein and KU70 protein forms a heterodimer (ie: KU protein), heterodimer and DNA-PK catalytic subunit (DNA-PKes) composition of DNA-PK [14]. When the XRCC5 gene mutates, the structure of the encoded $\mathrm{Ku} 80$ protein may change, it will cause $\mathrm{Ku} 80$ protein and $\mathrm{Ku} 70$ protein cannot bind or reduce the ability to bind, and will affect the heterodimer formation, so that the ability to mobilize DNA-PKes decreased, DNA-PK cannot play a normal role [15]. The non-homologous end repair function cannot be carried out, which may lead to the occurrence of tumor.

It has been recently reported that a significant increase in XRCC5 expression in hepatocellular carcinoma mice can prevent liver tumors induced by DNA damage [16]. However, the role of the XRCC5 gene in astrocytomas has not been studied. Functional prediction of rs9288516 using software FASTSNP, suggested that rs9288516 might cause a change in the potential binding sites of transcription factors, which may result in instability of XRCC5 messenger RNA transcripts, resulting in dysfunction of XRCC5 expression and ultimately lead to cancer [17]. 
Table 3: Analysis of the effect of genetic polymorphisms on the overall survival of astrocytoma by Univariate cox regression analysis

\begin{tabular}{|c|c|c|c|c|c|c|c|}
\hline Gene & SNP & Genotype & $\begin{array}{l}\text { Death cases/ } \\
\text { Total cases }\end{array}$ & $\begin{array}{c}\text { 1,3 year } \\
\text { overall } \\
\text { survival rate }\end{array}$ & $\begin{array}{c}\text { median } \\
\text { survival } \\
\text { time }\end{array}$ & $p$ & HR(95\%CI) \\
\hline \multirow{6}{*}{ XRCC5 } & \multirow{4}{*}{ rs3770502 } & $\mathrm{G} / \mathrm{G}$ & $99 / 107$ & $44.9 \% / 5.9 \%$ & 11 & 0.597 & 1 \\
\hline & & $\mathrm{A} / \mathrm{G}$ & $46 / 50$ & $44 \% / 6.7 \%$ & 10 & & $1.05(0.74-1.49)$ \\
\hline & & $\mathrm{A} / \mathrm{A}$ & $2 / 3$ & $33.3 \% /-$ & 12 & & $0.55(0.14-2.22)$ \\
\hline & & $\mathrm{T} / \mathrm{T}$ & $43 / 47$ & $25 \% /-$ & 12 & 0.049 & 1 \\
\hline & \multirow[t]{2}{*}{ rs9288516 } & $\mathrm{A} / \mathrm{T}$ & $78 / 85$ & $27.1 \% / 6.4 \%$ & 11 & & $1.2(0.83-1.75)$ \\
\hline & & $\mathrm{A} / \mathrm{A}$ & $43 / 47$ & $17.9 \% /-$ & 9 & & $1.69(1.04-2.77)$ \\
\hline \multirow{3}{*}{ XRCC4 } & \multirow{3}{*}{ rs 1056503} & $\mathrm{G} / \mathrm{G}$ & $75 / 83$ & $51.8 \% / 8.6 \%$ & 12 & 0.267 & 1 \\
\hline & & $\mathrm{G} / \mathrm{T}$ & $55 / 59$ & $35.6 \% / 4.1 \%$ & 10 & & $1.29(0.91-1.82)$ \\
\hline & & $\mathrm{T} / \mathrm{T}$ & $17 / 18$ & $44.4 \% /-$ & 9 & & $1.24(0.73-2.09)$ \\
\hline \multirow{5}{*}{ XRCC3 } & \multirow{2}{*}{ rs3212092 } & $\mathrm{C} / \mathrm{C}$ & $135 / 148$ & $46.6 \% / 7.2 \%$ & 11 & 0.145 & 1 \\
\hline & & $\mathrm{T} / \mathrm{C}$ & $12 / 12$ & $16.7 \% /-$ & 9 & & $1.49(0.83-2.71)$ \\
\hline & \multirow{3}{*}{ rs861530 } & $\mathrm{A} / \mathrm{A}$ & $41 / 45$ & $51.1 \% /-$ & 12 & 0.812 & 1 \\
\hline & & $\mathrm{A} / \mathrm{G}$ & $70 / 78$ & $41 \% / 9.3 \%$ & 11 & & $1.05(0.71-1.54)$ \\
\hline & & $\mathrm{G} / \mathrm{G}$ & $36 / 37$ & $45.9 \% / 2.7 \%$ & 11 & & $1.14(0.73-1.79)$ \\
\hline
\end{tabular}

$p<0.05$ indicates statistical significance.

HR: hazard ratios; CI: confidence interval.

\section{Survival Functions}

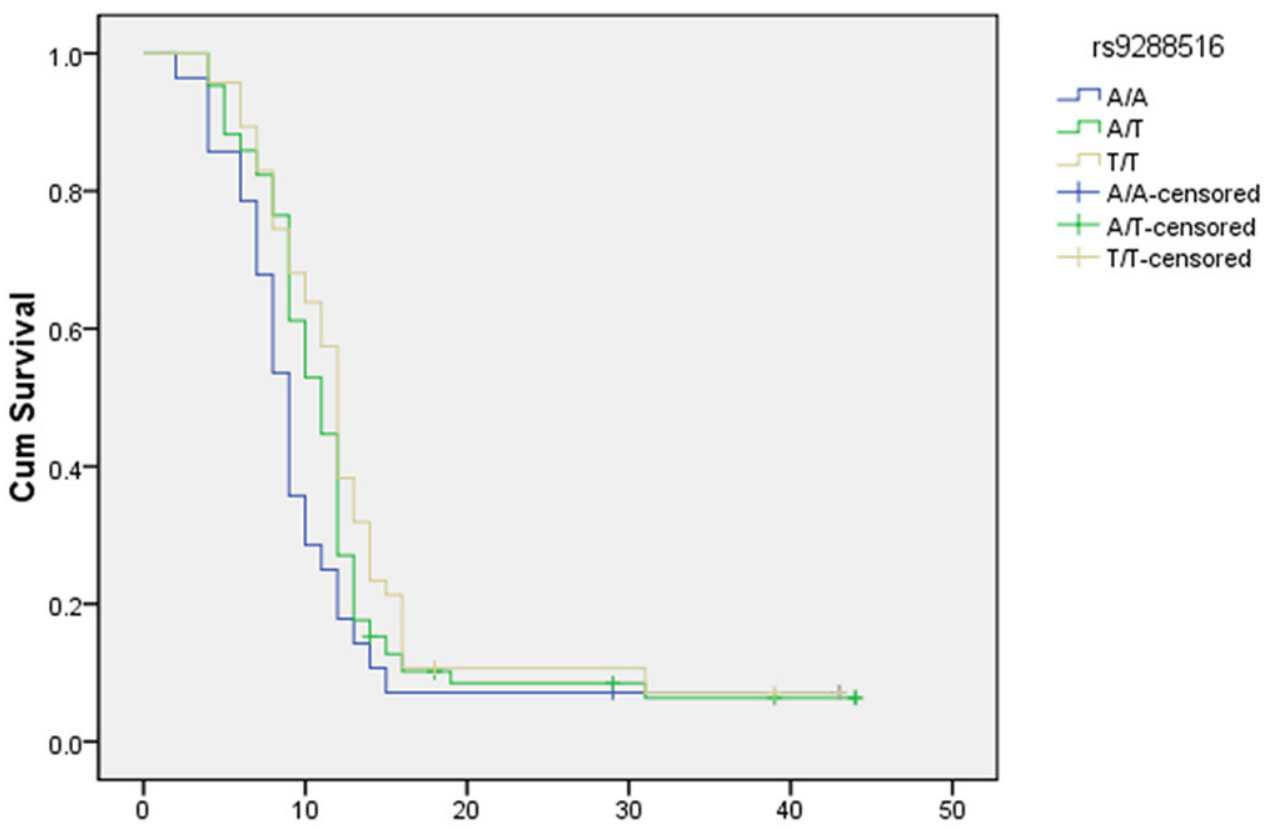

Overall survival

Figure 1: Kaplan-Meier analysis of overall survival is shown for different genotypes of rs 9288516 of XRCC5. 
Table 4: Analysis of the effect of genetic polymorphisms on the prognostic of astrocytoma by Multivariate cox regression analysis

\begin{tabular}{|c|c|c|c|c|}
\hline Gene & SNP & Genotype & $p$ & HR(95\%CI) \\
\hline \multirow{6}{*}{ XRCC5 } & \multirow{3}{*}{ rs 3770502} & $\mathrm{G} / \mathrm{G}$ & 0.629 & 1 \\
\hline & & $\mathrm{A} / \mathrm{G}$ & 0.683 & $1.08(0.76-1.53)$ \\
\hline & & $\mathrm{A} / \mathrm{A}$ & 0.401 & $0.55(0.13-2.24)$ \\
\hline & \multirow{3}{*}{ rs9288516 } & $\mathrm{T} / \mathrm{T}$ & 0.122 & 1 \\
\hline & & $\mathrm{T} / \mathrm{A}$ & 0.22 & $1.27(0.87-1.84)$ \\
\hline & & $\mathrm{A} / \mathrm{A}$ & 0.042 & $1.67(1.02-2.72)$ \\
\hline \multirow{3}{*}{ XRCC4 } & \multirow{3}{*}{ rs1056503 } & $\mathrm{G} / \mathrm{G}$ & 0.264 & 1 \\
\hline & & $\mathrm{T} / \mathrm{G}$ & 0.103 & $1.34(0.94-1.91)$ \\
\hline & & $\mathrm{T} / \mathrm{T}$ & 0.593 & $1.16(0.68-1.96)$ \\
\hline \multirow{5}{*}{ XRCC3 } & \multirow{2}{*}{ rs 3212092} & $\mathrm{C} / \mathrm{C}$ & - & 1 \\
\hline & & $\mathrm{T} / \mathrm{C}$ & 0.095 & $1.66(0.92-3.02)$ \\
\hline & \multirow{3}{*}{ rs861530 } & $\mathrm{A} / \mathrm{A}$ & 0.794 & 1 \\
\hline & & $\mathrm{A} / \mathrm{G}$ & 0.551 & $1.13(0.76-1.67)$ \\
\hline & & $\mathrm{G} / \mathrm{G}$ & 0.552 & $1.15(0.73-1.80)$ \\
\hline
\end{tabular}

$p<0.05$ indicates statistical significance with adjusted for surgical approach and chemotherapy

HR: hazard ratios; CI: confidence interval.

In our study, we regarded "A/A" of rs9288516 as an increased factor, which was just associated with prognostic effect of astrocytoma in Chinese patients. Compared with the previous studies, we found that XRCC5 gene is not a risk factor, can be used as a negative factor with prognostic effect of glioma. Our finding suggested that this gene may play a different role in complex diseases. In further studies, we should investigate the different mechanisms of XRCC 5 gene in different diseases. So that it is worth to pay more attention to explore the role of XRCC5 gene in variety cancers.

Although we have found that the XRCC5 gene may affect the prognosis of astrocytoma patients, there are still some problems that need to be improved in this study. For example, our sample size is relatively small, we should expand the sample in-depth study. Sometimes, individuals may carry risk alleles that will affect the outcome to the extent. So that the interactions effect of gene-environment should be explore in the furture.

\section{Conclusion}

In conclusion, we investigated an association between $X R C C 3, X R C C 4$ and $X R C C 5$ gene polymorphism and the risk and prognosis of astrocytoma in Chinese Han population. We have found evidence suggesting that the genotypes of XRCC5 may be correlated with increased risk and poor prognosis for astrocytoma. However, the exact mechanism of how the polymorphisms in the related the gene regulate astrocytoma prognosis needs to be further investigated.

\section{MATERIALS AND METHODS}

\section{Study participants}

All astrocytoma patients were Chinese Han who were followed up from December 2010 to April 2014, recruited from the department of Neurosurgery at Tangdu Hospital, Xian City, China. A total of 160 subjects were newly-diagnosed with pathologically verified astrocytoma in this study. Clinical information was collected and regularly updated for the patients with glioma through follow-up and questionnaires. These data include date of age, gender, date of diagnosis of primary tumor, date of surgical resection and surgery extent, treatment with chemotherapy and/or radiotherapy for primary and/or recurrent lesions, date of last followup, and status of patient (living/deceased) at the time of last follow-up. We excluded patients with the secondary astrocytoma from a primary cancer and patients received cetuximab at any step as part of their treatment were also excluded. 
All participants were informed of the procedures and purpose of the study, and each participant provided signed informed consent forms. The use of samples was approved by the Clinical Research Ethics of Xizang Minzu University and the Tangdu Hospital board.

\section{Selection of SNPs and methods of genotyping}

Five SNPs from 3 genes, previously reported that those gene were associated with glioma, were chosen for analysis in the current study [6-8]. $5 \mathrm{~mL}$ of whole blood sample was collected from each individual. DNA was separated from peripheral blood lymphocytes using the Gold Mag-Mini Purification Kit (Gold Mag Co. Ltd. Xian city, China). DNA concentrations were measured using the NanoDrop 2000 (Thermo Scientific, Waltham, Massachusetts, USA). Multiplexed SNP MassEXTENDED assay was designed by SequenomMassARRAY Assay Design 4.0 Software (Sequenom Co. Ltd., San Diego, CA, USA) [18]. SNP genotyping with a standard protocol was performed using SequenomMassARRAY RS1000 (Sequenom Inc., San Diego, CA, USA) [18]. SequenomTyper 4.0 Software (Sequenom Inc., San Diego, California, USA) was used to analyze the data $[18,19]$.

\section{Statistical analysis}

OS was defined as the time from the date of pathologically confirmed to the date of death or last clinical follow-up. PFS was calculated from the date of the pathologically confirmed to the progression of the disease, death without progression, or last clinical follow-up. We computed basic descriptive statistics for age at diagnosis, gender, WHO grade, extent of surgery, radiation therapy, chemotherapy, and frequencies of five SNPs. Survival distributions were estimated by using the Kaplan-Meier method and difference in the survival was tested using the log-rank test. To estimate the association of the five SNPs with PFS and OS in astrocytoma, the HR and $95 \%$ CI were calculated by Univariate Cox proportional hazards model. Multivariate Cox model were performed to compute adjusted HR and $95 \% \mathrm{CI}$, after adjusting for potential risk factors. All tests were two-sided and $p<0.05$ was considered to be significant. All statistics were conducted by SPSS 17.0 (SPSS, Chicago, IL, USA).

\section{ACKNOWLEDGMENTS}

This work was funded by the National Natural Science Foundations (No. 81560516) and Major science and technology research projects of Xizang (Tibet) Autonomous Region (2015XZ01G23).

\section{CONFLICTS OF INTEREST}

The authors have no conflicts of interest to report.

\section{REFERENCES}

1. Wen PY, Kesari S. Malignant gliomas in adults. The New England journal of medicine. 2008; 359:492-507.

2. Albert FK, Forsting M, Sartor K, Adams HP, Kunze S. Early postoperative magnetic resonance imaging after resection of malignant glioma: objective evaluation of residual tumor and its influence on regrowth and prognosis. Neurosurgery. 1994; 34:45-60; discussion 60-41.

3. Stummer W, Reulen HJ, Meinel T, Pichlmeier U, Schumacher W, Tonn JC, Rohde V, Oppel F, Turowski B, Woiciechowsky C, Franz K, Pietsch T, Group AL-GS. Extent of resection and survival in glioblastoma multiforme: identification of and adjustment for bias. Neurosurgery. 2008; 62:564-576; discussion 564-576.

4. Lamborn KR, Chang SM, Prados MD. Prognostic factors for survival of patients with glioblastoma: recursive partitioning analysis. Neuro-oncology. 2004; 6:227-235.

5. Wrensch M, Wiencke JK, Wiemels J, Miike R, Patoka J, Moghadassi M, McMillan A, Kelsey KT, Aldape K, Lamborn KR, Parsa AT, Sison JD, Prados MD. Serum IgE, tumor epidermal growth factor receptor expression, and inherited polymorphisms associated with glioma survival. Cancer research. 2006; 66:4531-4541.

6. Liu Y, Zhang H, Zhou K, Chen L, Xu Z, Zhong Y, Liu H, Li R, Shugart YY, Wei Q, Jin L, Huang F, Lu D, Zhou L. Tagging SNPs in non-homologous end-joining pathway genes and risk of glioma. Carcinogenesis. 2007; 28:1906-1913.

7. Liu Y, Zhou K, Zhang H, Shugart YY, Chen L, Xu Z, Zhong Y, Liu H, Jin L, Wei Q, Huang F, Lu D, Zhou L. Polymorphisms of LIG4 and XRCC4 involved in the NHEJ pathway interact to modify risk of glioma. Human mutation. 2008; 29:381-389.

8. Zhou K, Liu Y, Zhang H, Liu H, Fan W, Zhong Y, Xu Z, Jin L, Wei Q, Huang F, Lu D, Zhou L. XRCC3 haplotypes and risk of gliomas in a Chinese population: a hospital-based case-control study. International journal of cancer. 2009; 124:2948-2953.

9. Stummer W, Meinel T, Ewelt C, Martus P, Jakobs O, Felsberg J, Reifenberger G. Prospective cohort study of radiotherapy with concomitant and adjuvant temozolomide chemotherapy for glioblastoma patients with no or minimal residual enhancing tumor load after surgery. Journal of neuro-oncology. 2012; 108:89-97.

10. Stewart LA. Chemotherapy in adult high-grade glioma: a systematic review and meta-analysis of individual patient data from 12 randomised trials. Lancet (London, England). 2002; 359:1011-1018. 
11. Long XD, Zhao D, Wang C, Huang XY, Yao JG, Ma Y, Wei ZH, Liu M, Zeng LX, Mo XQ, Zhang JJ, Xue F, Zhai B, Xia Q. Genetic polymorphisms in DNA repair genes XRCC4 and XRCC5 and aflatoxin B1-related hepatocellular carcinoma. Epidemiology (Cambridge, Mass). 2013; 24:671-681.

12. Song L, Robson T, Doig T, Brenn T, Mathers M, Brown ER, Doherty V, Bartlett JM, Anderson N, Melton DW. DNA repair and replication proteins as prognostic markers in melanoma. Histopathology. 2013; 62:343-350.

13. Bau DT, Tsai CW, Wu CN. Role of the XRCC5/XRCC6 dimer in carcinogenesis and pharmacogenomics. Pharmacogenomics. 2011; 12:515-534.

14. Coffey G, Campbell C. An alternate form of Ku80 is required for DNA end-binding activity in mammalian mitochondria. Nucleic acids research. 2000; 28:3793-3800.

15. Olive PL. The role of DNA single- and double-strand breaks in cell killing by ionizing radiation. Radiation research. 1998; 150:S42-51.
16. Reliene R, Goad ME, Schiestl RH. Developmental cell death in the liver and newborn lethality of Ku86 deficient mice suppressed by antioxidant $\mathrm{N}$-acetyl-cysteine. DNA repair. 2006; 5:1392-1397.

17. Yuan HY, Chiou JJ, Tseng WH, Liu CH, Liu CK, Lin YJ, Wang HH, Yao A, Chen YT, Hsu CN. FASTSNP: an always up-to-date and extendable service for SNP function analysis and prioritization. Nucleic acids research. 2006; 34:W635-641.

18. Gabriel S, Ziaugra L, Tabbaa D. SNP genotyping using the Sequenom MassARRAY iPLEX platform. Current protocols in human genetics/editorial board, Jonathan L Haines [et al]. 2009; Chapter 2:Unit 2.12.

19. Thomas RK, Baker AC, Debiasi RM, Winckler W, Laframboise T, Lin WM, Wang M, Feng W, Zander T, MacConaill L, Lee JC, Nicoletti R, Hatton C, Goyette M, Girard L, Majmudar K, et al. High-throughput oncogene mutation profiling in human cancer. Nature genetics. 2007; 39:347-351. 